\title{
Prepubic Urethrostomy in Male Cat - Modified Technique
}

\author{
Horia Elefterescu DMV, BcVSc, PhD vet, MD, PhD MD, BcBiol* \\ Veterinary Clinic, Vetlife, Bucharest, Romania \\ *Corresponding Author: Horia Elefterescu, Veterinary Clinic, Vetlife, Bucharest, \\ Romania.
}

DOI: $10.31080 /$ ASVS.2020.02.0048
Received: January 28, 2020

Published: February 18, 2020

(C) All rights are reserved by Horia

Elefterescu.

\section{Abstract}

Post operatively complications after the perineal urethrostomy in cat males, as obstruction of urethra, narrowing or occlusion of urethra have been documented in general practice. Salvage procedure of prepubic urethrostomy, was applied with high rate of success on 100 cases between 1992-2019. Prepubic urethrostomy is a valuable alternative of the perineal urethrostomy. Because of the risk of having a too short urethra the modified technique involved pubic symphysiotomy and dissection of intrapelvic urethra and relocation of it on the prepubic area.

Keywords: Prepubic Urethrostomy; Male; Cat

\section{Introduction}

The significant cases presented to the clinic with significant trauma of the intrapelvic urethra after unsuccessful catheterization of the urethral obstruction, urethral trauma/stricture or failed perineal urethrostomy led us to use the prepubic urethrostomy in order to save the life of the animal [1]. During the years 1992 - 2019 a number of 100 cases were treated using the modified technique. The surgery was done on stable animals only, for that reason in the study were not mentioned any other investigations (bloods, urinalysis, abdominal U/S, etc). The study was focused only to evaluate the technique in its self and its limits among to other techniques only on stabile patients. The pubic symphysiotomy was applied in order to obtain a longer urethra [2] which provided us enough length of urethra to be fixed to the skin reducing considerable the risk of damaging of urinary bladder's sphincter followed by different degrees of incontinence [3].

\section{Materials and Methods}

The study included 100 castrated cat males or entire which underwent perineal urethrostomy or suffered damage of the intrapelvic urethra.

Surgical technique: The cat is placed in dorsal recumbency and clipped and aseptically prepared for a celiotomy. A ventral celiotomy [4] is made from the umbilicus and is continued with a pubic symphysis osteotomy and ends with the prepuce (Figure 1). With a thin osteotome the pubic symphysis is opened and pelvic conduct exposed (Figure 2). Using blunt dissection, the urethra is mobilized from the pelvic canal alongside with the penis (Figure 3). The urethra is mobilised and placed cranially to the pubis bone. The pubis symphysis is closed using one or two cerclage wire [5]. Urethra is cut close to prostate or caudal to prostate but in this case, prostate is removed as much as possible. First suture point of the celiotomy will be close to the pubic symphysis. Urethra will lay on this suture. Next starting point of closing the celiotomy will be about 8-10 mm apart to that first suture and the celiotomy is closed routinely. The end of urethra is cut longitudinally that half will be placed cranially and half caudally (Figure 4). The urethral mucosa is sutured to the skin with 1.5 - $1 \mathrm{M}$ monofilament suture material using a simple interrupted suture pattern (Figure 5). The subcutaneous tissue and skin is closed in a routine manner (Figure 6) [6]. In 50 cases cystotomy was performed and the urinary bladder was lavaged with isotonic saline solution for washing out all of the small uroliths. The bladder was closed in 2 layers with 1.5 - $1 \mathrm{M}$ monofilament suture material using a simple interrupted suture pattern.

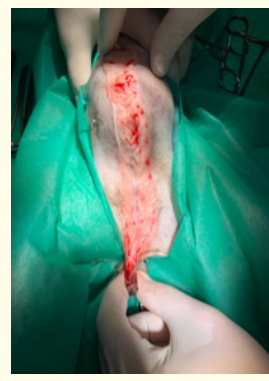

Figure 1: Line of incision. 


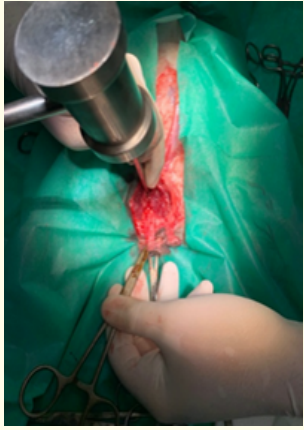

Figure 2: Pubic osteotomy.

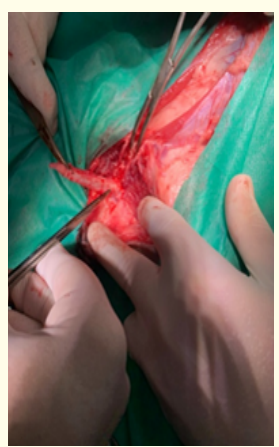

Figure 3: Blunt dissection of urethra.

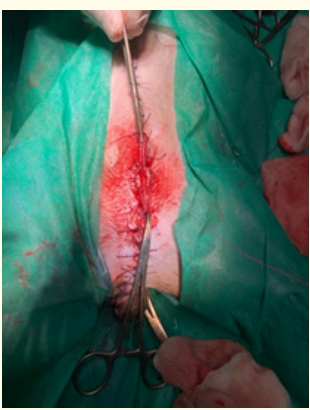

Figure 4: Urethra cut longitudinally.

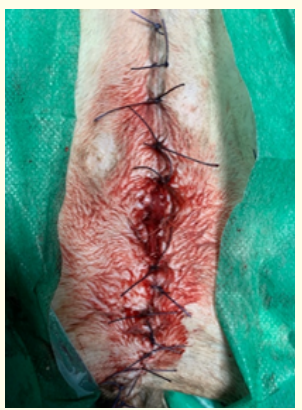

Figure 5: Final aspect of the Urethrostomy.

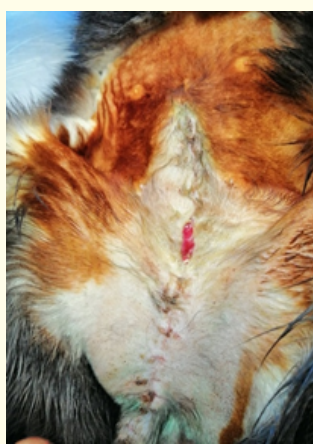

Figure 6: Three weeks post operatively.

\section{Results and Discussion}

Results after this prepubic urethrostomy were very good [7]. The results were $0 \%$ incontinence, $5 \%$ stoma strictures all caused because of very poor postoperatively care of the owner at home and $2 \%$ skin necrosis around the stoma in two extremely overweight cats with poor self-grooming, $0 \%$ of leakage of the urine under the skin at the urethrostomy sutures and $0 \%$ urinary tract infection during first 2 years post operatively.

All cases returned to the clinics from where they were referred and we received periodically the feedback regarding the patient evolution. Unfortunately, after approximatively 2 years, many cases were lost but approximatively $30 \%$ of them remained in contact with their practice for at least 5-8 years.

\section{Conclusion}

The prepubic urethrostomy with pubic symphysiotomy offers an excellent alternative to the classic technique reducing the postoperatively complication mentioned in literature

\section{Clinical Relevance}

Prepubic urethrostomy with pubic symphysiotomy is a comparatively a complex procedure that should be considered as a salvage technique for obstructive disease of the pelvic urethra.

\section{Bibliography}

1. Ellison GW., et al. "Subpubic Urethrostomy to Salvage a Failed Perineal Urethrostomy in a Cal". The Compendium - Small Animal 11 (1989).

2. Baines SJ., et al. "Prepubic urethrostomy: A long-term study in 16 cats". Veterinary Surgery 30.2 (2001): 107-113.

3. Brockman DJ. "Lower Urinary Tract Salvage Options". World Small Animal Veterinary Association World Congress Proceedings (2013). 
4. Johnston SA and Tobias KM. "Veterinary Surgery Small Animal”. Second Edition, Ed. Elsevier (2017).

5. Fossum T. “Small Animal Surgery”. 4th edition, Elsevier (2012).

6. Ladlow JF. "Feline Soft Tissue and General Surgery". Ed Elsevier (2014).

7. Elefterescu H. "Perineal and Abdominal Urethrostomy in the Male Cat-Comparative Study". World Small Animal Veterinary Association World Congress Proceedings (2001).

\section{Assets from publication with us}

- Prompt Acknowledgement after receiving the article

- Thorough Double blinded peer review

- Rapid Publication

- Issue of Publication Certificate

- High visibility of your Published work

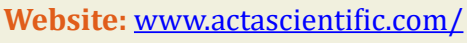

Submit Article: www.actascientific.com/submission.php

Email us: editor@actascientific.com

Contact us: +919182824667 